\title{
Behavior of Curtain Walls - Heating Reduction of Buildings in Summer Situations or in Hot Climates
}

\author{
M. Walsdorf-Maul and F.U. Vogdt
}

\begin{abstract}
The choice of building components is of a great influence on the energy performance of buildings. In cold climates building components determine the dimensions of transmission- and ventilation-heat-loss and are crucial to thermal comfort. But on the other hand in hot climates the amount of solar heat gain depends on the building components too. A distinction is drawn between direct and diffuse solar radiation on transparent and non-transparent (opaque) components. While the solar radiation can reduce the heating demand in winter situation of cold climates, an increased cooling requirement is assumed for hot climates. For transparent components it is possible to offer a sun protection device or a low total energy transmission of glazing (g-value). This prevents the heating-up of buildings and keeps the cooling requirements low.

Curtain walls are characterized in their thermal behavior primarily by the properties of thermal insulation material and the micro-climatic conditions in the air layer. In this context the question arises how the air layer thickness and the surface behavior influence the solar heat gain.

This paper deals with experimental studies of the behavior of curtain walls and their influence to reduce the cooling requirement. For this purpose the air layer thickness is varied and different surfaces are investigated.
\end{abstract}

Index Terms-Behavior of curtain walls, reduction of cooling requirement, air layer thickness, surface influence.

\section{INTRODUCTION}

For a long time, in Europe there was a special attention about the winter heat protection instead of the summer comfort. Since the introduction of the Energy Saving Regulation in Germany the summer situation gets more important particularly with regard to the cooling requirement of buildings.

The German standards DIN V 18599 [1] and DIN EN ISO 13790 offer the possibility to calculate the energy use for space heating and cooling. In Table I the basic equations are presented.

One of four factors calculating the heat sources is the solar heat gain. The solar heat gain in (3) in Table I consists of transparent and non-transparent (opaque) components. Basically the transparent component has the higher influence and plays a more important role. Therefore many investigations were performed. But it can be assumed that the air layer of a curtain wall construction dissipates the heat flux and reduces the ambient temperatures inside the buildings in a summer situation.

Manuscript received December 9, 2012; revised March 18, 2013.

Manuela Walsdorf-Maul and Frank U. Vogdt, University of Technology, Berlin (e-mail:

bauphysik@tu-berlin.de).
Equation (5) in Table I does not differ between curtain walls and a solid wall with insulation to calculate the solar gains of non-transparent components. Only the heat transfer coefficient could influence the cooling requirement indirectly.

TABLE I: DIN V 18599 - BASIC EQUATIONS [1]

\begin{tabular}{|c|c|}
\hline primary energy $\left(Q_{p}\right)$ & $\begin{array}{l}\qquad Q_{p}=\sum\left(Q_{f, j} \cdot \frac{f_{p, j}}{f_{H S / H I, j}}\right) \\
\text { with } \mathrm{Q}_{\mathrm{f}, \mathrm{j}} \text { for final energy demand of energy source, } \\
\mathrm{f}_{\mathrm{p}, \mathrm{j}} \text { for primary energy factor, } \mathrm{f}_{\mathrm{HS} / \mathrm{HI}, \mathrm{j}} \text { as a conversion } \\
\text { factor }\end{array}$ \\
\hline $\begin{array}{l}\text { cooling requirement } \\
\left(Q_{c, b}\right)\end{array}$ & $\begin{array}{c}Q_{c, b}=(1-\eta) \cdot Q_{\text {source }} \\
\text { with } \eta \text { for utilisation factor, } \mathrm{Q}_{\text {source }} \text { for heat sources }\end{array}$ \\
\hline heat sources $\left(Q_{\text {source }}\right)$ & $\begin{array}{l}Q_{\text {source }}=Q_{S}+Q_{T}+Q_{V}+Q_{I, \text { source }} \\
\text { with } \mathrm{Q}_{\mathrm{s}} \text { for solar heat gain, } \mathrm{Q}_{\mathrm{T}} \text { for transmission heat } \\
\text { gain, } \mathrm{Q}_{\mathrm{V}} \text { for ventilation heat gain }\end{array}$ \\
\hline $\begin{array}{l}\text { solar heat of gain } \\
\left(Q_{s}\right)\end{array}$ & $\begin{array}{l}Q_{S}=\sum Q_{S, t r}+\sum Q_{S, o p} \\
\text { with } \mathrm{Q}_{\mathrm{s}, \mathrm{tr}} \text { for solar heat gains of transparent } \\
\text { components, } \mathrm{Q}_{\mathrm{s}, \mathrm{op}} \text { for solar heat gains of } \\
\text { non-transparent components }\end{array}$ \\
\hline $\begin{array}{l}\text { solar heat gains of } \\
\text { non-transparent } \\
\text { components }\left(Q_{s, o p}\right)\end{array}$ & $\begin{array}{l}Q_{S, o p}=R_{s e} \cdot U \cdot A \cdot\left(\alpha \cdot I_{s}-F_{f} \cdot h_{r} \cdot \Delta \vartheta_{e r}\right)(5) \\
\text { with Rse for heat transmission resistance, } \mathrm{U} \text { for heat } \\
\text { transfer coefficient, } \alpha \text { for absorption coefficient, } \mathrm{I}_{\mathrm{s}} \\
\text { for solar radiation, } \mathrm{F}_{\mathrm{f}} \text { for form factor of construction } \\
\text { and sky, } \mathrm{h}_{\mathrm{r}} \text { for emission coefficient and } \Delta \vartheta_{e r} \text { for } \\
\text { mean difference between ambient temperature and } \\
\text { sky temperature }\end{array}$ \\
\hline
\end{tabular}

The aim of the studies is to determine the heat flux $Q$ which is transported in the air layer and may reduce the cooling requirement in summer situation. Already well known from the available literature [2] the heat flux Q in a vertical conduit based on the heat transfer area is

$$
Q=\alpha \cdot A \cdot\left(\vartheta_{w}-\vartheta_{E}\right)
$$

This equation is an approximation to the solution of the heat flux. Temperatures are determined easily by measuring but not the heat transfer coefficient $\alpha$. This coefficient depends on the conductivity of air in the air layer and the Nusselt number [3] as well as indirectly on the Rayleigh and their Grashof and Prandtl numbers [3]. In consequence many factors influence the heat transfer coefficient.

The main objective of this paper is to investigate the influence of solar radiation for the air layer but also 
temperature distribution inside at the surface of the curtain wall. The work is divided in two parts: modeling the experimental set-up and laboratory investigations. This paper focuses on laboratory investigations of the air layer thickness and the surface influence. At first the experiment set-up is explained. At second the investigated variants are presented. The paper finishes with an evaluation section and a conclusion.

\section{EXPERIMENT SET-UP}

The objective of the experiments is the investigations of the air layer of the curtain wall by variation thickness and surface behavior. The indoor experiment seeks the creation of a natural convection mechanism along the facade by means of the difference of temperature between the surface temperatures inside the air layer. The facade elements are heated up by short-wave radiation from the solar simulator. The solar-simulator is installed at the laboratory of the Civil Engineering Department of the University of Technology Berlin (Germany) and attempts to imitate outdoor solar lighting conditions by emitting a short-wave radiation beam. Therefore, the simulator consists of $18(3 \times 6)$ Leon Virgola $330 \mathrm{~W}$ halogen spotlights with three adjustable performance dimmer mounted on an aluminum structure as can be seen in Fig. 1 and Fig. 2 displays the thermal image of surface after heating. It is seen that the surface is heated up relatively uniform. The experiment set-up requirements create surface temperature that approximates real situations; reduce forced convection much as possible and allows measurement of velocity of airflow, ambient air, air layer und surface temperature. Certainly some characteristics of the solar simulator and laboratory where the experiment set-up is being installed can produce undesirable effects. Heating up the floor may lead to a long-wave radiation and convective heat transfer. Therefore an aluminum reflective layer finishing to the floor may reduce surface heating, long-wave radioactive and convective heat flux [4].

Fig. 2 illustrates the experiment set-up design. The dimensions of the test specimen are $125 \times 310 \mathrm{~cm}^{2}$. Beginning inside, the curtain wall consists with fibre cement tile, thermal insulation, fibre cement tile, an air layer and a fibre cement tile positioned ahead to solar simulator (Fig. 3). One additional fibre cement tile arranged between air layer and thermal insulation shall facilitate measurements at first.

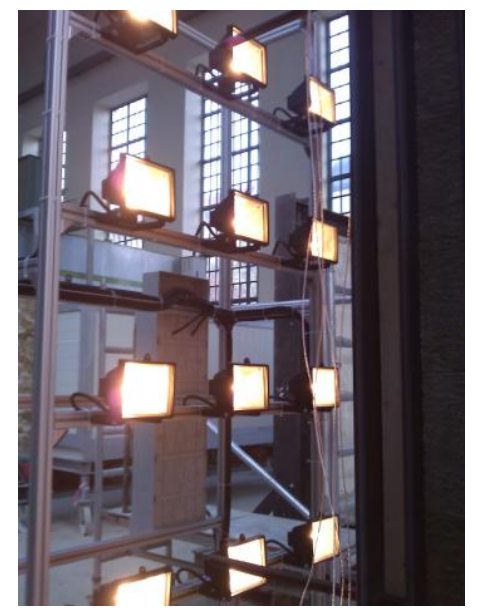

Fig. 1. Solar simulator.
The experiment set-up is designed to allow a series of measurements of air velocity and temperature. For temperature measurements, 24 sensors (Pt100) are mounted on the curtain wall: 22 sensors at the surface inside the air layer and 2 at the surface outside of the construction. For the air velocity measurements, seven sensors with a hot-wire probe are mounted between the air layer. Measurements will be performed at the surface and in the air layer.

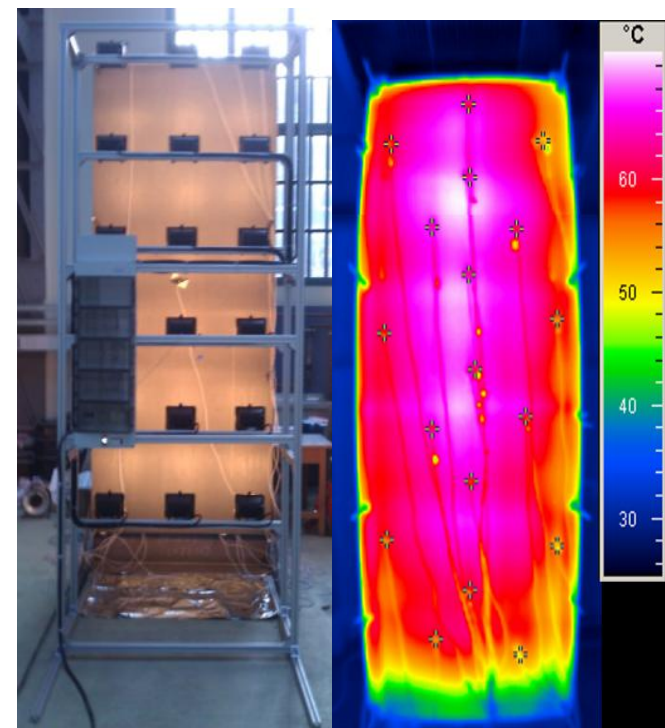

Fig. 2. Experiment set-up (left), thermal image (right).

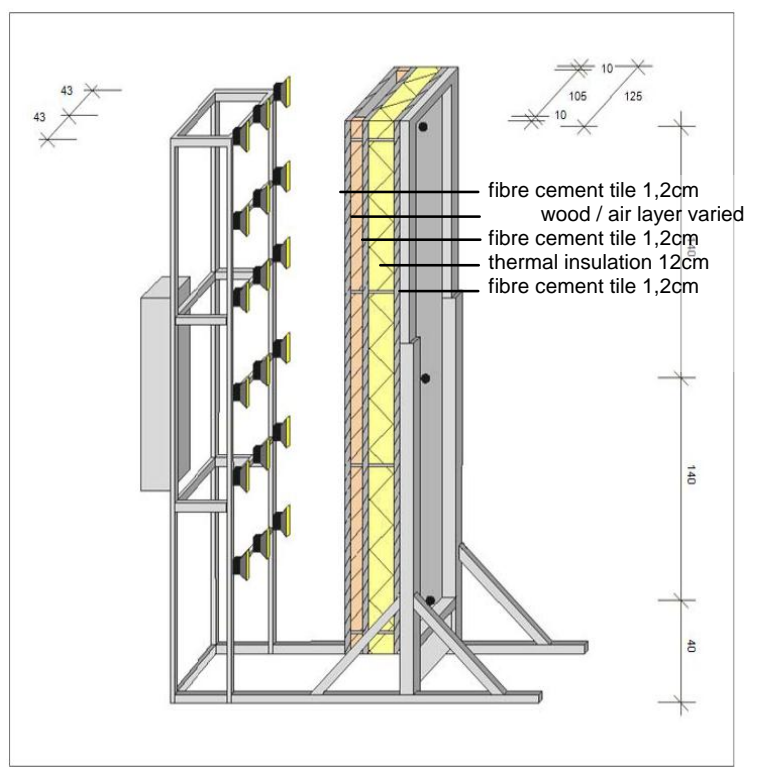

Fig. 3. Dimensions and composition of experiment set-up. [4]

\section{LABORATORY INVESTIGATION}

\section{A. Thickness of Air Layer}

This paper deals with the investigations of three different thicknesses: $5.5 \mathrm{~cm}, 7.2 \mathrm{~cm}$ and $10.5 \mathrm{~cm}$. These dimensions depend on wooden spacers which are made of chipboard.

To investigate the surface temperature inside of the air layer 32 sensors are fastened evenly over the height of the wall. Two more temperature sensors are positioned for measuring the air temperature. The positioning of sensors is shown in Fig. 4. In addition to consider the temperatures the air velocity is measured in 3 measure points in the middle of 
the air layer.

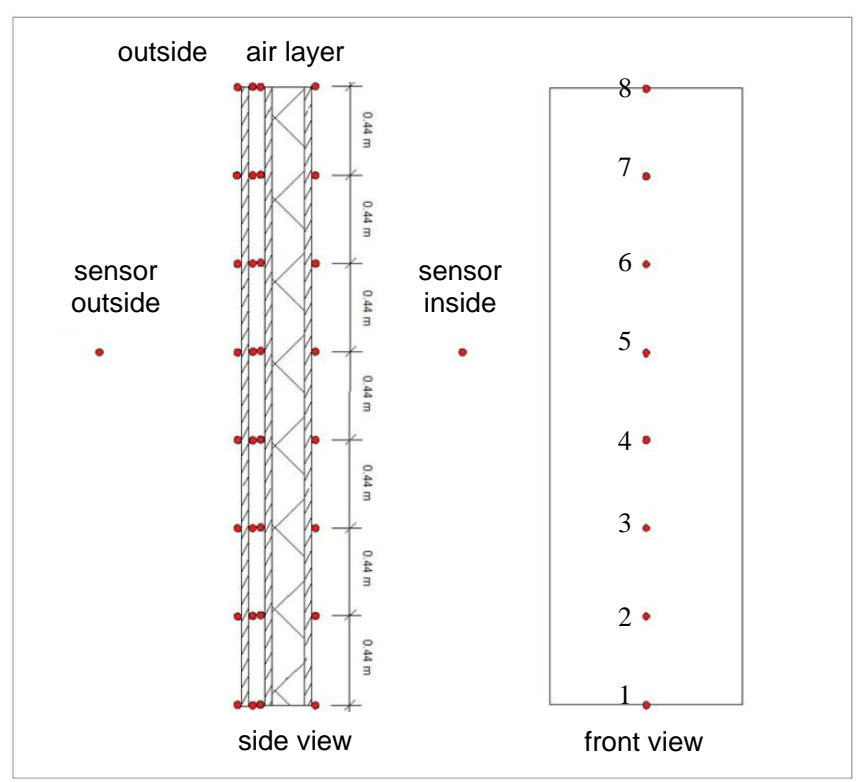

Fig. 4. Positioning of temperature sensors, experimental set-up I. [4]

\section{B. Influence of Surface Condition}

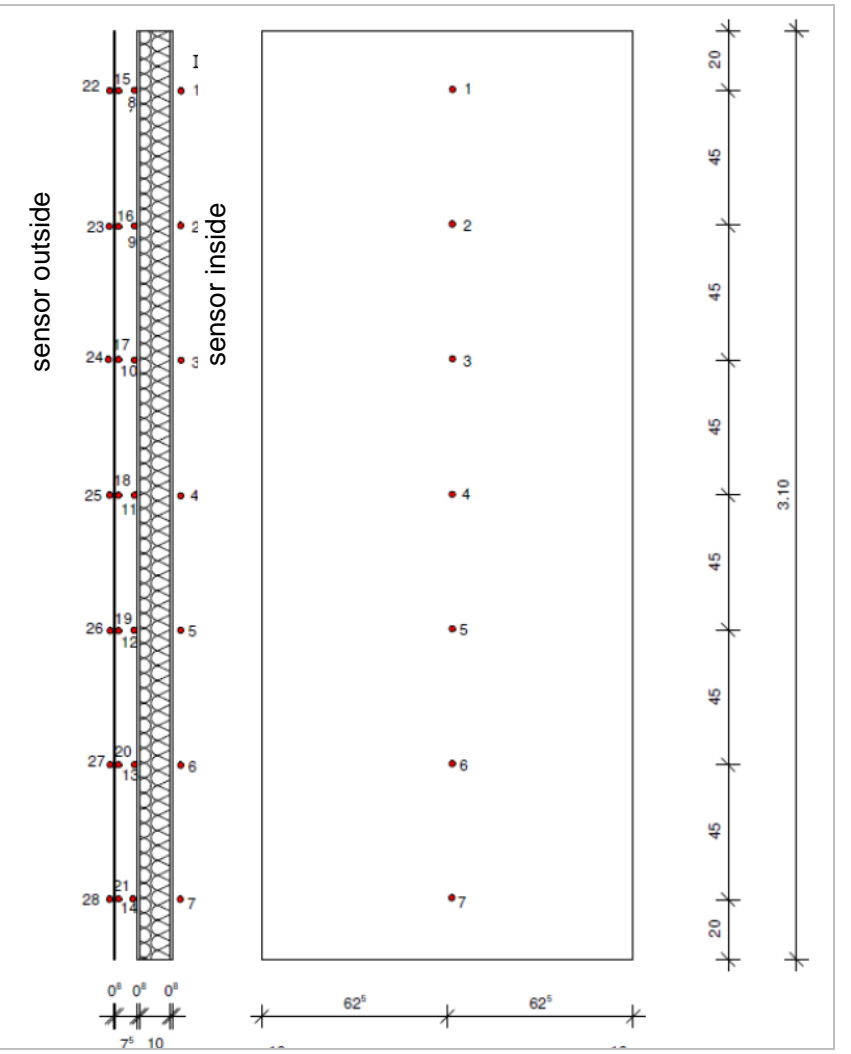

Fig. 5. Positioning of temperature sensors, experimental set-up II. [5]

This part of paper deals with investigations about the influence of the surface conditions. Therefore 9 different variations of surface conditions are investigated. The thickness of the air layer is about $7.5 \mathrm{~cm}$ and remains the same for all investigations. In all cases the curtain wall is exposed to the same light intensity. Basically three different colors for the surface condition of the fibre cement tile are chosen: black, white and silver. Table I shows the different measurements with the variations of colors.
TABLE I: VARIATION OF SURFACE CONDITIONS

\begin{tabular}{llll}
\hline \hline measurements & $\begin{array}{l}\text { fibre cement tile } \\
\text { outside }\end{array}$ & $\begin{array}{l}\text { fibre cement tile } \\
\text { inside }\end{array}$ & shortcut \\
\hline 1 & white & white & mess1 \\
2 & silver & white & mess2 \\
3 & silver & silver & mess3 \\
4 & white & silver & mess4 \\
5 & black & white & mess5 \\
6 & black & silver & mess6 \\
7 & silver & black & mess7 \\
8 & white & black & mess8 \\
9 & black & black & mess9 \\
\hline \hline
\end{tabular}

Different to the experimental set-up shown in Fig. 4 in this part of investigation 28 temperature sensors are used. The positioning is shown in Fig. 5.

\section{EVALUATIONS AND RESUlts}

\section{A. Thickness of Air Layer}

Considering the different thicknesses of the air layer the curtain wall is heated up to $60.4^{\circ} \mathrm{C}$. The heating process needs 5 hours to reach a steady state. Table II shows the results of the measured temperature differences depending on the air layer thickness.

TABLE II: TEMPERATURE DIFFERENCES $\Delta \Theta$ IN THE AIR LAYER

\begin{tabular}{llll}
\hline \hline $\begin{array}{l}\text { measure } \\
\text { point }\end{array}$ & $\begin{array}{l}5.5 \mathrm{~cm} \\
\text { air layer }\end{array}$ & $\begin{array}{l}7.2 \mathrm{~cm} \\
\text { air layer }\end{array}$ & $\begin{array}{l}10.5 \mathrm{~cm} \\
\text { air layer }\end{array}$ \\
\hline 1 & $4.66 \mathrm{~K}$ & $6.54 \mathrm{~K}$ & $8.23 \mathrm{~K}$ \\
2 & $22.36 \mathrm{~K}$ & $22.13 \mathrm{~K}$ & $22.54 \mathrm{~K}$ \\
3 & $14.74 \mathrm{~K}$ & $16.67 \mathrm{~K}$ & $16.10 \mathrm{~K}$ \\
4 & $12.68 \mathrm{~K}$ & $14.62 \mathrm{~K}$ & $11.37 \mathrm{~K}$ \\
5 & $14.80 \mathrm{~K}$ & $13.18 \mathrm{~K}$ & $14.02 \mathrm{~K}$ \\
6 & $13.85 \mathrm{~K}$ & $8.76 \mathrm{~K}$ & $8.60 \mathrm{~K}$ \\
7 & $13.11 \mathrm{~K}$ & $11.51 \mathrm{~K}$ & $15.29 \mathrm{~K}$ \\
8 & $2.63 \mathrm{~K}$ & $8.63 \mathrm{~K}$ & $8.58 \mathrm{~K}$ \\
\hline
\end{tabular}

It is obvious that the temperatures at the entry (measure point 1 ) and also at the exit (measure point 8 ) of the curtain wall are lower compared to the other measure points. Table II shows also that there is no definite tendency about the air layer thickness. But considering the results in total the temperature differences in the air layer indicate that the heat escapes through the air layer of the curtain wall. This might be a great chance for reducing the heating of buildings by the sun and consequently it might reduce the cooling requirement.

To analyze the phenomena of the air layer it is necessary to look over surface temperatures, temperature distributions, air velocity but also to consider the air flow. Therefore the Grashof and Reynolds numbers give some information about flow characteristic behavior of the air layer. Fig. 6 shows the distribution of the Grashof number depending of the height. 


\section{Grashof distribution}

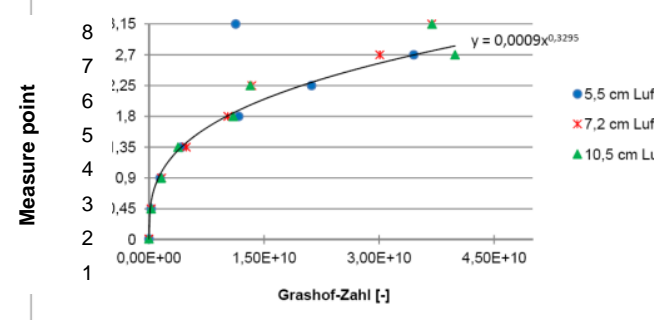

Fig. 6. Grashof distribution depending on the height of curtain wall. [4]

Similar to the Reynolds number the Grashof number defines the type of air flow for the natural convection. A Grashof number with $\mathrm{Gr}_{\text {krit }}=1.3 \cdot 10^{7}$ is the limit where the air flow change from a laminar to a turbulent condition. A turbulent flow is reached from $\mathrm{Gr}_{\text {krit }}=4.0 \cdot 10^{7}$. In Fig. 6 it is obvious that entering into the air layer (measuring position 1) the air is in a laminar flow. But not far away from the entry the air turns into turbulent flow. With increasing height the turbulent air flow becomes stronger. In our case calculations have demonstrated that air flow transits from turbulent to laminar after $3 \mathrm{~cm}$ behind entering the air layer. The air flow behavior is independent of the air layer thickness.

\section{B. Influence of Surface Condition}

In this part of paper the influence of chosen colors of fibre cement tile is investigated. While Table III shows the surface temperature at the outside, Table IV displays the temperature differences in the air layer.

TABLE III: SURFACE TEMPERATURE $\Theta$ AT THE OUTSIDE IN ${ }^{\circ} \mathrm{C}$

\begin{tabular}{llllllllll}
\hline \hline m. & mess & mess & mess & mess & mess & mess & mess & mess & mess \\
point & 1 & 2 & 3 & 4 & 5 & 6 & 7 & 8 & 9 \\
\hline 1 & 48.8 & 45.6 & 45.9 & 54.2 & 65.6 & 66.5 & 47.9 & 52.4 & 67.6 \\
2 & 53.2 & 46.4 & 48.0 & 56.6 & 67.9 & 69.6 & 46.1 & 54.5 & 69.7 \\
3 & 52.0 & 43.6 & 45.5 & 52.3 & 65.2 & 67.3 & 46.0 & 52.1 & 65.9 \\
4 & 50.5 & 47.1 & 48.3 & 56.8 & 66.5 & 69.6 & 46.8 & 55.4 & 64.6 \\
5 & 49.5 & 45.7 & 47.1 & 55.6 & 64.1 & 68.8 & 47.1 & 53.0 & 62.2 \\
6 & 47.2 & 45.6 & 46.8 & 53.7 & 63.1 & 67.4 & 45.9 & 51.3 & 63.0 \\
7 & 37.8 & 42.6 & 42.4 & 47.6 & 49.2 & 53.4 & 44.2 & 45.4 & 53.2 \\
\hline \hline
\end{tabular}

TABLE IV: TEMPERATURE DIFFERENCES $\Delta \Theta$ IN THE AIR LAYER IN K

\begin{tabular}{llllllllll}
\hline \hline m. & mess & mess & mess & mess & mess & mess & mess & mess & mess \\
point & 1 & 2 & 3 & 4 & 5 & 6 & 7 & 8 & 9 \\
\hline 1 & 5.7 & 5.7 & 7.1 & 14.3 & 10.5 & 28.4 & 3.2 & 6.0 & 6.2 \\
2 & 7.6 & 5.0 & 5.9 & 15.6 & 14.0 & 28.3 & 2.9 & 7.7 & 10.7 \\
3 & 4.8 & 4.0 & 5.3 & 13.3 & 11.5 & 23.4 & 1.5 & 5.0 & 7.3 \\
4 & 6.6 & 8.0 & 9.9 & 18.1 & 14.3 & 31.1 & 6.3 & 9.2 & 12.1 \\
5 & 6.5 & 3.0 & 9.9 & 15.4 & 12.0 & 30.8 & 4.7 & 5.9 & 9.7 \\
6 & 5.4 & 7.0 & 8.3 & 16.9 & 15.5 & 26.9 & 6.7 & 7.8 & 11.9 \\
7 & 6.1 & 6.1 & 4.9 & 9.5 & 11.8 & 20.1 & 4.4 & 3.6 & 5.6 \\
\hline \hline
\end{tabular}

TABLE V: TEMPERATURE $\Theta$ INSIDE THE AIR LAYER AT THE INSULATION IN

\begin{tabular}{llllllllll}
\multicolumn{10}{c}{${ }^{\circ} \mathrm{C}$} \\
\hline \hline $\mathrm{m}$. & mess & mess & mess & mess & mess & mess & mess & mess & mess \\
\hline 1 & 1 & 2 & 3 & 4 & 5 & 6 & 7 & 8 & 9 \\
\hline 2 & 30.2 & 35.1 & 32.6 & 33.8 & 54.0 & 36.9 & 34.8 & 39.4 & 54.4 \\
3 & 40.8 & 33.2 & 30.4 & 31.3 & 53.2 & 35.6 & 33.9 & 39.9 & 53.9 \\
4 & 36.7 & 32.9 & 34.0 & 52.8 & 37.1 & 35.9 & 41.2 & 53.0 \\
5 & 38.4 & 31.6 & 28.9 & 30.1 & 49.4 & 33.3 & 31.8 & 37.5 & 48.9 \\
6 & 34.8 & 30.8 & 31.1 & 50.2 & 33.4 & 34.0 & 38.7 & 49.7 \\
7 & 31.0 & 32.1 & 29.4 & 28.7 & 45.0 & 31.9 & 31.9 & 35.2 & 44.8 \\
\hline \hline
\end{tabular}

The colours of the fibre cement tile have a great influence by absorption, reflection and emission. With the view of the absorption coefficient the black surface reaches the highest temperatures (mess 5, 6 and 9). Consequently the silver surface obtains the lowest surface temperatures (mess 2, 3 and 7). Similar to this result white surfaces prevent also the heating of the surface.

With a view to table IV it is obvious that also the emission plays a role for the air layer temperature conditions. The biggest temperature difference is found with outside black and inside silver surface (mess 6). As a result if black and silver are changed on the surface there are the lowest temperature differences (mess 7). This phenomenon might be also caused by the maximum temperature on the surface.

Table $\mathrm{V}$ displays the temperature inside of the air layer at the insulation. Therefore the lowest temperatures are found for the combination of silver-silver surface. Black as a colour outside and black or white for the inside surface, this combinations obtain the highest temperature at the insulation layer.

Fig. 7 shows the air velocity depending on heating time. About 250 minutes of heating time the experiment changes from an in steady state to a steady state.

As a result the highest surface temperature outside and also the greatest temperature differences affect the highest air velocity into air layer (mess 9).

The lowest air velocity is reached by the silver-silver surface. For this combination the surface temperature outside is one of the lowest but not regarding the temperature differences.

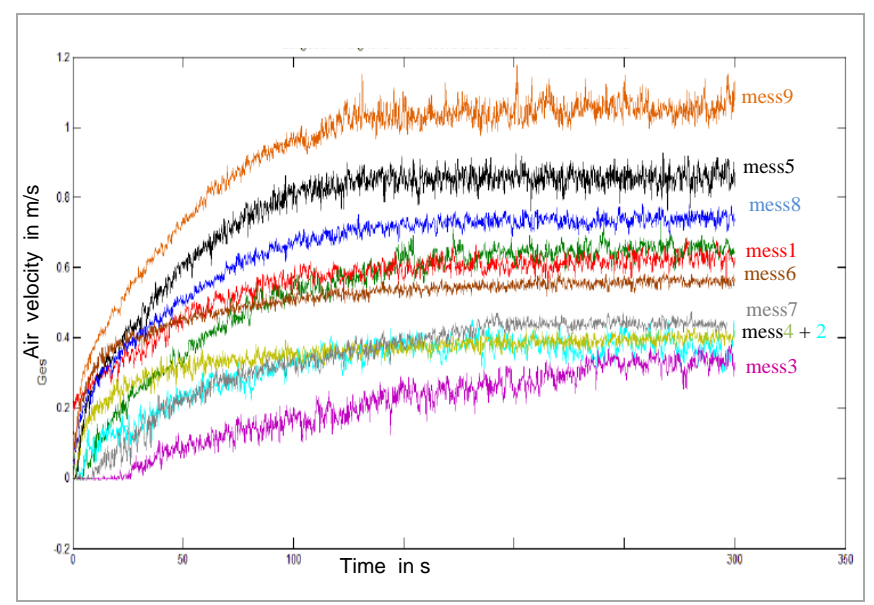

Fig. 7. Air velocity in the middle of air layer. [5]

\section{CONCLUSION}

In total it is noted that there is a high potential for reducing the solar heat gain by using curtain walls. The air layer offers the possibility for the heat to escape. With the investigated choice of air layer thickness the air velocity and also the temperature differences are independent from the air layer thickness. In fact the surface condition has a great influence on the outside surface temperature and also on temperature differences in the air layer. Black surfaces reach the highest surface temperature, silver the lowest. The combination of black outside and silver inside the air layer gets the highest surface temperature outside and also the greatest temperature 
difference inside and a high temperature at the insulation layer. A low surface temperature outside and the smallest temperature difference inside are reached by the combination silver outside and black inside. The lowest temperature at the insulation layer is found for the combination silver-silver.

In conclusion it is shown that two ways might minimize the solar heat gain: in the first point of view it is comfortable to obtain a low temperature using white or silver surfaces for the outside of the curtain wall. On the other side there might be a way for black surfaces outside of the curtain wall by using inside of the air layer a silver surface to obtain a great temperature difference in the air layer. The aim is to reach the lowest temperature at the surface of the insulation.

Last but not least more investigations are necessary. It is obvious that there might be a potential to reduce the heating of buildings and therefore, to minimize the cooling requirement. It seems to be interesting to find a way for including these facts in the German calculation method of DIN V 18599.

In the view of climate policy, resource conservation and environmental protection using curtain walls might be the chance to prevent the heating of buildings by sun in particular for hot climates. As a consequence the electricity requirements for cooling drop and therefore the environmental impact is reduced.

\section{REFERENCES}

[1] Energy efficiency of Buildings: Calculations of the net, final and primary energy demand for heating, cooling, ventilation, domestic hot water and lighting, DIN V 18599-2: 2007-02.

[2] R. Marek, K. Nitsche, Praxis der Wärmeübertragung, Fachbuchverlag Leipzig, 2010.

[3] VDI-Wärmeatlas, VDI-Gesellschaft. Springer-Verlag. 2006.
[4] J. M. Alessandrini, J. Gilles, J. B. Rieunier, and B. Zeghondy, "Summer comfort in attics: solar factor and operative temperature," in Proceedings of the 4th International Building Physics Conference (4th IBPC), Istanbul, Turkey, June 15-18, 2009, pp. 885-892, 2009.

[5] A. Werth, "Untersuchung der Abhängigkeit zwischen Querschnittsänderungen der Luftschicht und den Temperaturen einer hinterlüfteten Fassade (Study oft he dependence between cross-section changes of the layer o fair and the temperatures of a back-ventilated facade)," B.Sc. thesis 2012 (unpublished)

[6] F. Wüsthoff, "Untersuchung des Einflusses unterschiedlicher Oberflächen von Fassadenbekleidungen auf die Wärmetransportmechanismen einer Luftschicht (Analysis oft he influence of different surfaces of cladding on the heat transmission mechanism of an air layer)," B.Sc. thesis 2012 (unpublished)

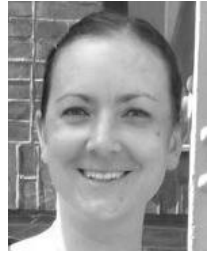

Manuela Walsdorf-Maul is scientific employee at Technische Universität Berlin at the chair of Building Physics and Building Constructions since 2007. Since 12/2011 she is Technical expert for energetic building design.a reference. Current and previous research interests ends the paragraph.

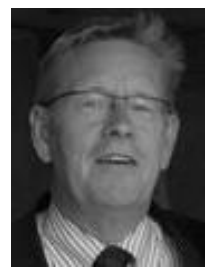

Frank U. Vogdt is the head of the section (Univ.-Prof.) of the chair of Building physics and Building Constructions at Technische Universität Berlin since 2007. 